\title{
Structural heterogeneities of tube steels taken into account in the development of contactless magnetometry of pipeline systems
}

\author{
Boris Ermakov ${ }^{1 *}$, Sergey Ermakov ${ }^{1}$, Oksana Nikiforova ${ }^{1}$ and Nikita Shaposhnikov ${ }^{1}$ \\ ${ }^{1}$ Peter the Great Saint-Petersburg Polytechnic University, 29, Polytechnicheskaya st., Saint \\ Petersburg, 195251, Russian Federation
}

\begin{abstract}
Annotation. One of the problems facing gas and oil pumping companies is the aging of pipelines, whose service life is rapidly approaching, or even exceeding, the resource planned during design. The only possible way to evaluate the possibility of further safe operation and residual life of pipelines is to conduct studies of the actual state of the parent metal and welded pipe joints. However, the direct investigation of metal pipes is practically impossible due to the linear dimensions of objects and their position. The analysis of the state of the pipeline system can only be made with the help of contactless, most often magnetic methods. Interpretation of magnetograms and detection of defects that are dangerous for the operation of pipes is one of the most difficult problems facing defectoscopists, which can be solved only by creating a library of structures and defects. This paper presents the results of a structural analysis of the metal of pipes, which must be taken into account when interpreting the results of magnetograms. These results constitute a part of the library of defects in pipeline systems developed in SPbPU.
\end{abstract}

Introduction. The global resource base of hydrocarbons, the geographic location of the country, the developed system of gas and oil pipelines, with linkages to different countries of Europe and Asia, make Russia the center of pipeline geopolitics. The country has developed and is successfully implementing a program for the design and construction of such intercontinental and transnational pipeline systems that have a marine position, such as the Nord Stream-2, the TurkStream and others. The wide development of the offshore deposits of the Arctic shelf is planned. The operation of offshore pipelines, which are, as a rule, high pressure pipelines, make increased requirements for the reliability and safe operation of facilities, which should be ensured, in particular, by improvement of the quality and volume of current monitoring of the pipeline condition. This can be achieved only by developing and creating fundamentally new control systems, among which the most promising are the non-contact magnetometric control systems. However, additional investigations of the magnetometric control should be preceded by additional studies of the base metal and welded joints of the pipes, which allows to describe the magnetic states and structures of the metal and the processes occurring in the crystalline magnetic structures of tube steels during long-term operation under external and operational influences. These impacts, first of all, include the corrosive effects of the external environment, deformations and stresses that arise in the pipeline during land displacement and subsidence, under the influence of permanent and seasonal currents and so on. [1,2].

The first stage in the introduction of non-contact magnetometry should be the description of magnetic structures and processes occurring in tube steels during their production and operation and the construction of a physical and mathematical model of the magnetic state of the metal of pipes.

Techniques. Considering that all magnetic structures and magnetic transformations occurring in the tube steel are formed during the formation of its structural constituents and

\footnotetext{
* Corresponding author: s.b.ermakov@bk.ru
} 
under the effect on these constituents of the thermal deformation factor - rolling, welding; corrosion and deformation processes during long-term operation, it is necessary to clarify the general structural heterogeneity inherent in all tube steels. On the basis of that knowledge, a generalized approach may be formed to understanding the magnetic structure of tubular steels and its changes in the course of long-term operation of the pipeline system. It's also necessary to specify the reasons leading to changes such as formation of zones of local deformations of pipes at movements of a pipe-line, occurrence of zones of corrosion defects and fissures of different nature.

This paper presents the study of microstructure of tube steels by optical and electron microscopy, microspectral analysis and ESCA (electron spectroscopy for chemical analysis), the chemical compositions of non-metallic inclusions and grain boundaries of steel were studied, the textures of steel blanks were investigated by X-ray diffraction analysis.

Results and discussion. The main material of modern pipelines is high-strength lowalloy steels containing, in addition to manganese and silicon, microalloying elements. When combined with thermal and mechanical treatments during slab heating, hot rolling and cooling, the elements affect the microstructure, grain size and properties of steel. Highstrength low-alloy steels have developed significantly after the optimal ratio of alloying and micro-alloying elements has been found, which allows to obtain a good complex of strength and plastic characteristics along with high low-temperature viscosity and weldability at low cost and employing simple production technology. The advantage of using steel with higher strength characteristics is a significant reduction in the weight of the finished structures. At the same time, the increase in the strength of steel must necessarily be accompanied by an increase in its viscosity. This imposes certain requirements on the microstructure of highstrength tube low-alloy steels $[3,4]$. The welded pipe for gas and oil pipelines consists of more than $99 \%$ of the base metal and less than $1 \%$ of the welding seam, so the main properties of the pipes are provided not only in pipe plants but also in metallurgical plants during steel smelting, its thermoplastic processing on rolling mills, which is especially noticeable in the case of controlled rolling [5, 6]. Tube steels are heterogeneous and incomplete, both in composition and in their structure - macro, micro and fine structure. The magnitude, nature and degree of uniformity of the distribution of these imperfections determines both the mechanical and magnetic properties of steels, their behavior during processing, their strength and performance in the specific operating conditions of the pipeline. Conventionally, the heterogeneity of the composition and imperfection of the structure of crystals and crystallites, and, consequently, the heterogeneity of the structure of a thin magnetic structure, on the basis of which magnetometric methods are based, can be divided into two types: biographical and processing [5-8].

Biographical imperfections [9, 10], first of all, are related to the initial composition of the alloy and the conditions of its crystallization. An example of such imperfection in real steels is zonal and dendritic liquation. Most elements in steel, including carbon, are segregating from the dendrite axis to the inter-axial spaces. The joint liquation of impurity elements can both enhance and weaken the degree of dendritic chemical inhomogeneity of alloyed steels. When forming the magnetic and mechanical properties of steel, it is not so much the interdendritic inhomogeneity itself that is important, but the banding of the structure associated with it- the formation of zones different in chemical composition and magnetic properties -ferrite-perlite (Fig. 1), the row arrangement of its individual constituents (nonmetallic inclusions, carbides). 


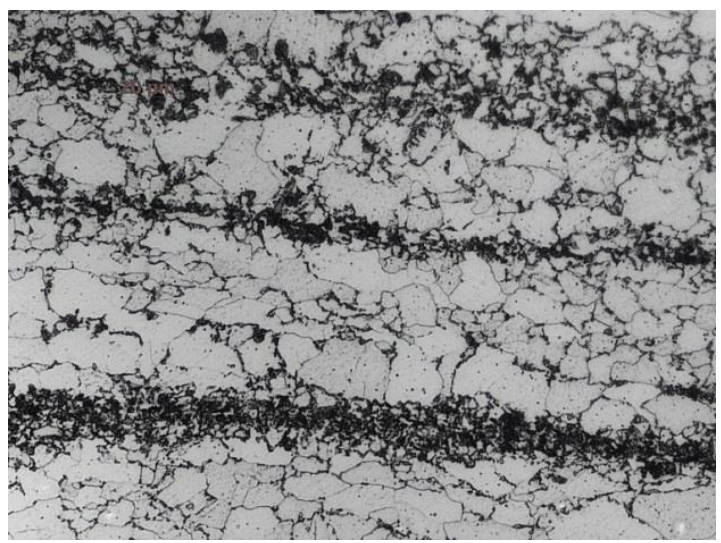

Fig.1. Banded orientation and difference in grain heterogeneity in X70 tube steel - 1420x22 tube at $1 / 2$ depth from the surface of the sheet. $x 500$

Processing imperfections can also influence the development of banding and the appearance of the effect of grain heterogeneity in steel. Processing imperfections are caused by the processes of heating - austenization and homogenization of the material, the conditions of its cooling; stress relieving and material aging. Due to these processes concretion of the carbide phase and formation of grain-boundary segregations of impurity atoms) $[11,12,15$, 16], is possible, in particular, the heterogeneity of deformation origin depends on the temperaturevelocity regime of deformation, the temperature of the steel heating before deformation and in the end of deformation, and also the degree of deformation (total and in the last stand, if rolling is carried out in several passes). Table 1 gives data on the magnitude of the steel heterogeneity in the pipe at different distances from the outer surface of the pipe.

Table 1. The grain size in the pipe metal at a depth of $1 / 4,1 / 2$, and $3 / 4$ from the outer surface

\begin{tabular}{|l|c|c|c|c|c|}
\hline \multirow{2}{*}{ Subject of control } & \multicolumn{5}{|c|}{ grain size, $\mu \mathrm{m} *$} \\
\cline { 2 - 6 } & $\begin{array}{c}\text { Outer } \\
\text { surface }\end{array}$ & $\begin{array}{c}1 / 4 \\
\text { thickness }\end{array}$ & Midsection & $\begin{array}{c}3 / 4 \\
\text { thickness }\end{array}$ & $\begin{array}{c}\text { Inner } \\
\text { surface }\end{array}$ \\
\hline $\begin{array}{l}\text { Average diameter } \\
\text { according to GOST } \\
5639, \mu \mathrm{m}\end{array}$ & $5-8$ & $6-9$ & $7-10$ & $7-9$ & $6-8$ \\
\hline $\begin{array}{l}\text { Average number of } \\
\text { grains per 0.01 mm * }\end{array}$ & 186 & 137 & 121 & 132 & 171 \\
\hline $\begin{array}{l}\text { Grain number in } \\
\text { accordance with } \\
\text { GOST 5639 }\end{array}$ & $11-12$ & 11 & $10-11$ & 11 & 11 \\
\hline $\begin{array}{l}\text { The average diameter } \\
\text { of the 50 "largest" } \\
\text { grains on an area of 1 } \\
\text { mm }\end{array}$ & 14 & 21 & 28 & 22 & 16 \\
\hline
\end{tabular}

* Note: Given that the tube steel is fine-grained, the area for counting the grains was chosen at the rate of $100 \times 100 \mu \mathrm{m}$.

As indicated in Table 1, the heterogeneity has practically no effect on the average grain size in steel determined by the method given in GOST 5639, which on an average remains within the 11 grain number, but the size of the 50 largest grains changes almost twofold from 14 to $28 \mu \mathrm{m}$, which leads to an intensification of the process of internal adsorption of impurities and alloying elements of steel - their segregation at the grain boundaries. As a result of the increase in the grain diameter, the total area of the boundaries surface decreases, for example, with the growth of austenite grains during high-temperature welding heating, 
when the concentration of the gorophilic element exceeds the solubility limit in the microvolume of the thermal welding seam zone during piping assembly. In this case, in the heat-affected zone of the welded joint, a local decomposition of the solid solution becomes possible, with separation of the dispersed particles of the excess phase and the development of segregations of impurity atoms, although the averaged composition of the steel is still far from reaching the solubility limit. [17], Table 2 gives data on the chemical composition of grain boundaries of X70 steel, depending on the location of the control (of the boundaries of coarse and fine grains in the base metal and metal adjacent to the longitudinal weld line) obtained by the method of electron spectroscopy for chemical analysis. The boundaries of the grain for analysis were opened during impact tests at $77 \mathrm{~K}$.

Table 2. Distribution of alloying and impurity elements in the grain boundaries of tube steel

\begin{tabular}{|c|c|c|c|c|c|c|c|}
\hline \multirow[b]{3}{*}{ Element } & \multicolumn{2}{|c|}{ Main metal } & \multirow[t]{2}{*}{ Weld line } & \multirow{3}{*}{ Element } & \multicolumn{2}{|c|}{ Main metal } & \multirow{2}{*}{$\begin{array}{l}\text { Weld } \\
\text { line }\end{array}$} \\
\hline & $1 *$ & 2 & & & 1 & 2 & \\
\hline & \multicolumn{3}{|c|}{$\begin{array}{l}\text { Content of elements, mass. } \\
\% \times 100\end{array}$} & & \multicolumn{3}{|c|}{$\begin{array}{c}\text { Content of elements, mass. } \\
\qquad \% \times 100\end{array}$} \\
\hline $\mathrm{C}$ & 132 & 147 & 192 & $\mathrm{Nb}$ & 318 & 335 & 382 \\
\hline Mo & 101 & 131 & 147 & $\mathrm{P}$ & 196 & 379 & 512 \\
\hline $\mathrm{Cr}$ & 189 & 187 & 218 & $\mathrm{Sb}$ & 214 & 312 & 425 \\
\hline $\mathrm{V}$ & 201 & 251 & 456 & $\mathrm{~Pb}$ & 316 & 464 & 486 \\
\hline $\mathrm{Ti}$ & 196 & 296 & 398 & $\mathrm{~S}$ & 119 & 189 & 217 \\
\hline
\end{tabular}

* Note - 1 - the area of the pipe metal adjacent to the outer surface; 2 - metal zone at a depth of $1 / 2$ from the surface

The fractographic and microspectral studies of the base metal and welded pipe joints were performed to determine the type and stoichiometric composition of nonmetallic inclusions. The analysis of nonmetallic inclusions was carried out on a sample of 20 pipes of various plants supplying pipe products. It was discovered that the main types of nonmetallic inclusions are calcium-oxide- $\mathrm{CaO}$ compounds or oxysulfide $\mathrm{CaO} * \mathrm{CaS}$, as well as aluminum oxides. There is also a significant part of the elements of the vanadium group $-\Sigma(\mathrm{Ti}+\mathrm{V}+$ $\mathrm{Nb}$ ) in nonmetallic inclusions.

Processes of plastic deformation of the tube billet not only lead to the occurrence of structural heterogeneities in steel, but also form it's texture, which can also affect the magnetic characteristics of the material. The most common description of the texture in the material is carried out with the help of direct pole figures (DPF), which are stereographic projections of the normals of the reflecting planes of the same type $\{h k l\}$. The DPF is characterized by those ideal orientations that correspond to the most intense maxima on the DPF. The curves of influence of the total intensity of each DPF ring from the slope angle of the $\alpha$ sample (textureogram) clearly illustrate the nature of the texture and the quantitative relationships between the various components of the texture and its non-texture component, and also show texture changes under the influence of various technological and operational factors [17-20]. 
The studies were carried out on ten X70 pipes with a diameter of $1420 \mathrm{~mm}$ in two sections along the pipe thickness - in $1 / 4$ and $1 / 2$ from the outer surface of the pipe. An example of the results of texture research is shown in Fig.2.

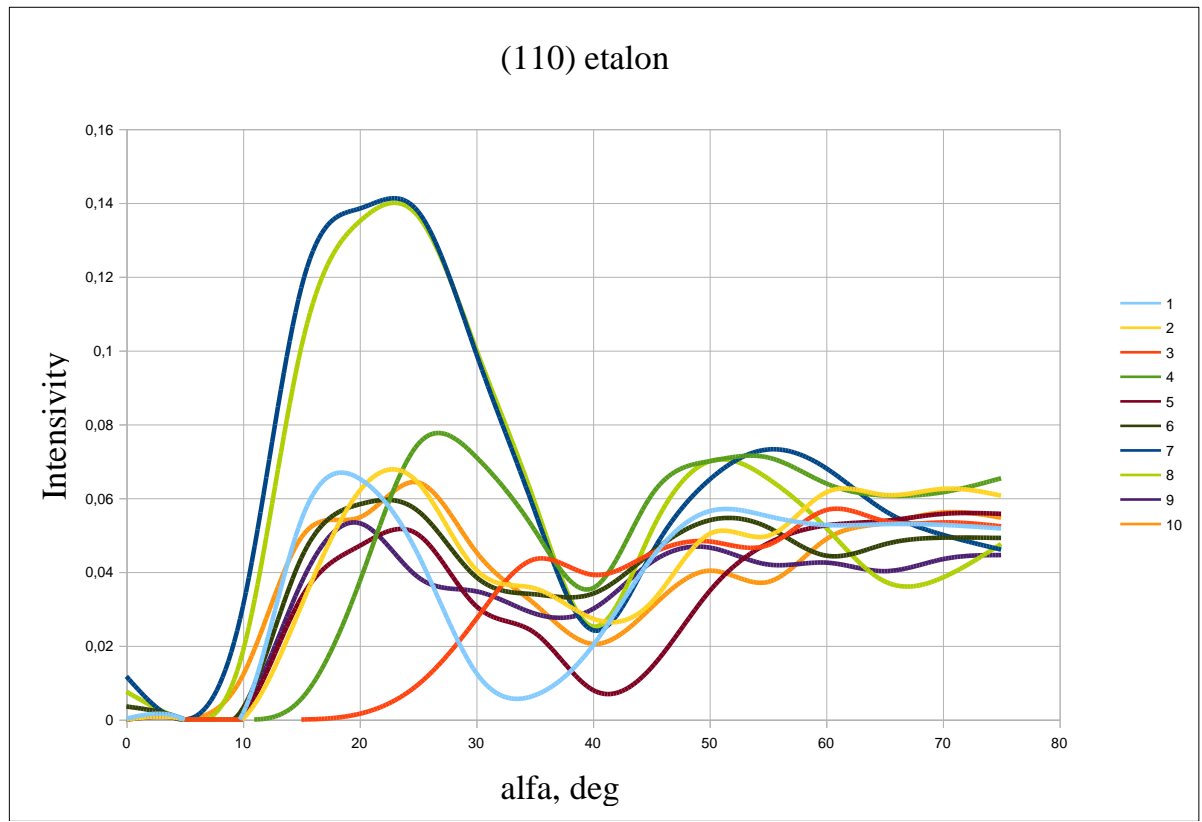

Fig. 2. A summary graph of texture patterns $\{110\}$ for the pipes № 1-10 (1/2 of the pipe thickness from the outer surface).

Data processing through the construction of DPF and their semiquantitative analysis made it possible to distinguish the following basic orientations of textures present in the metal of the pipes: $\{112\}\langle 110\rangle,\{001\}\langle 100\rangle\langle 110\rangle,\{110\}<001\rangle,\{111\}<110\rangle\langle 112\rangle,\{113\}$ $\langle 110\rangle$, relating to the deformation textures of the $\alpha$-phase, as well as its transformation. A semi-quantitative analysis of the DPF from the lines (110) (200) and (211) of the samples of different pipes gave the following distribution of the percentages of these orientations: the $\{110\}<001>$ orientation in $1 / 2$ varies from $1-2$ to $14 \%$ - the rest is the unstructured component; in $1 / 4$ the maximum content of the $\{110\}<001>$ orientation is $11 \%$. Thus, it was shown that against the background of the general unassembled component a number of textural orientations are present in the pipe material, the most significant of which is the $\{110\}<001>$ orientation, and the maximum proportion of this orientation is reached in the midsection of the pipes. For reflections (200) and (211), there were no obvious differences in thickness between all the pipes, and the percentage of presence of these orientations is extremely small.

Conclusion. Thus, while analyzing the structural state of tubular steels, a number of factors have been identified that must be taken into account when constructing a physicalmathematical model of the magnetic state of the material. Among such factors are the string structure of the material, the heterogeneity, the presence of nonmetallic inclusions and segregations of impurity and alloying elements, zones of plastic deformation of textural orientations in the metal of the pipe. Currently, SPbPU specialists together with ZAO POLIINFORM are carrying out a set of studies aimed at creating a physical and mathematical model of the magnetic state and changes in the magnetic structure of tube steels that will allow the introduction of a new contactless method for monitoring the actual state of pipelines based on magnetometric analysis of the state of the pipes.

1. A.G. Alekseev, P.A. Grigor'ev, B.V. Patramanskij, P.A. Halileev, Gazovaya promyshlennost, 20-21 (1) (1985) 
2. The resolution of the meeting of the scientific and technical task group of Russian oil and gas contractors union. (14.02.2007)

3. P.A. Halileev, B.V. Patramanskij, E.I. Zenin, V.E. Loskutov, G.S. Korzunin Defektoskopiya, 3-17 (1) (2000)

4. O.S. Kozhukhova, Voprosy ekonomiki i prava, 174-177 (7) (2011)

5. Yu.P. Solntsev, B.S. Ermakov, Resurs materialov nizkotemperaturnyh konstrukcij (2006)

6. A.E. Shubochkin, Thesis for the degree of Doctor of Technical Sciences (2014)

7. V.E. Shcherbinin, E.S. Gorkunov, Magnitnyj kontrol' kachestva metallov (1996)

8. S.M. Novokshchenova, M.I. Vinograd, Defekty stali (1984)

9. L.L. Medvedko, A.V. Shestopalov, Issues of Technical Sciences in the light of modern research 50-54 (2018)

10. A.N. Makovetsky, D.A. Mirzaev, Fizika metallov i metallovedenie , 656 (6(115), (2014)

11. L.I. Efron, Trubnye stali (2012)

12. V.M. Gorickij, Diagnostika metallov (2004)

13. A.V. Pomazova, Praktika protivokorrozionnoj zashchity 68-71 (3(69) (2013)

14. A.V. Pomazova, T.V. Panova, G.I. Goering, Vestnik Yuzhno-Ural'skogo gosudarstvennogo universiteta, 31-34 4 (14) (2014)

15. B.V. Patramansky, Thesis for the degree of candidate of technical sciences (2001)

16. O.A. Bagmet, Thesis for the degree of candidate of technical sciences (2007)

17. L.I. Efron, V.I. Ilinsky, A.V. Golovanov, Yu.D. Morozov, Stal', 69-72 (6) (2003)

18. Yu.P. Solntsev, B.S. Ermakov, Metally $i$ splavy, (2005)

19. I.V. Ehgiz, V.F. Shamraj, Metallovedenie i termicheskaya obrabotka metallov, 2001, 9-12 (2) (2001)

20. I.V. Ehgiz, V.F. Shamraj, Metallovedenie i termicheskaya obrabotka metallov, 2003, 33-36 (1) (2003)

21. N.P. Lyakishev, V.F. Shamray, Metally, 68-72 (2) (2000) 